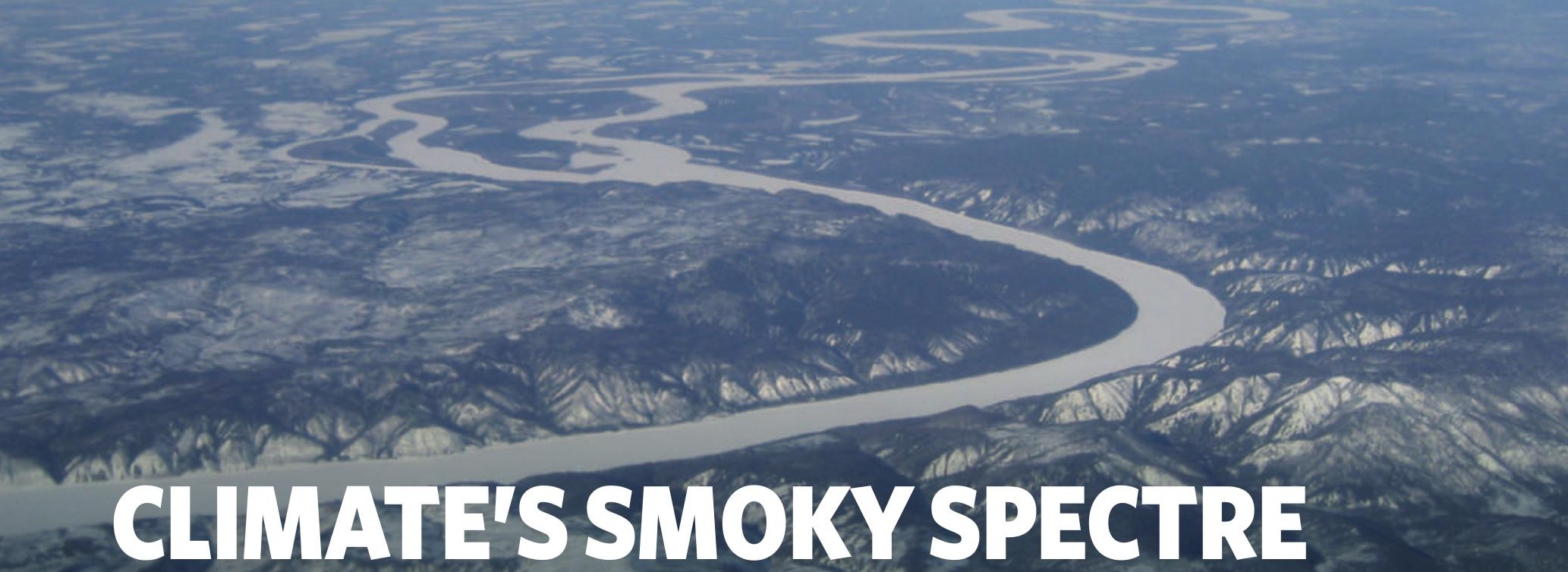
With their focus on greenhouse gases, atmospheric scientists have largely
overlooked lowly soot particles. But black carbon is now a hot topic among
researchers and politicians. Jeff Tollefson investigates.

$\int$ b teve Warren spent his spring break island-hopping with a couple of friends, but they didn't go to bask in the sun. Instead, his team from the University of Washington in Seattle toured the Canadian Arctic, digging pits in the snow and collecting hundreds of samples to take back to the lab. The targets of their expedition, hidden in all the whiteness, were specks of something called black carbon.

These dark particles, the major constituents of soot, are the legacy of incomplete combustion in diesel engines, coal power plants, agricultural burning and wildfires far to the south. Prevailing winds sweep black carbon and other pollutants into the Arctic, where they circulate in a dirty yellow haze (pictured above) until storms wash them out of the air. Warren's team was collecting those that fell among the snow flakes.

The aerosol haze has long plagued the Arctic, but scientists are only now taking stock of a different and potentially uglier dimension of soot. As its name would suggest, black carbon absorbs sunlight. These particles heat the atmosphere while aloft; when they settle on the snow, they hasten its melting. This exposes the dark land and water, which absorb more of the sun's energy and thereby drive up the region's temperature. Recent research ${ }^{1}$ suggests that black carbon could be responsible for a large fraction of the Arctic warming. Soot also takes a toll elsewhere. In southeast Asia, studies suggest $^{2}$ that it is choking the moisture supply for the Indian monsoons and contributing to the retreat of mountain glaciers that provide fresh water for more than a billion people.

At this point, scientists lack enough data to definitively conclude how strongly black carbon is affecting the climate. But some studies suggest that it could be second behind carbon dioxide in terms of its contribution to global
"Sea ice may be melting anyway, but black carbon can cause more melting and earlier melting." - Andreas Stohl warming. There is a crucial difference between the two pollutants, however: soot particles hang in the atmosphere for just a few weeks, whereas $\mathrm{CO}_{2}$ molecules can remain in the air for centuries. This means that efforts to curb soot emissions could reap immediate climatic benefits. That possibility has recently pulled soot, which has conventionally been seen as a public-health issue, into the climate-policy arena.

"There's an urgency about this: we still don't have a viable way of cutting down $\mathrm{CO}_{2}$," says Veerabhadran Ramanathan, an atmospheric scientist at Scripps Institution of Oceanography in La Jolla, California. By comparison, reducing soot emissions seems remarkably simple and cheap. "It's not going to take 30 or 100 years to do it. If you halt the black carbon now, it will be gone in two weeks."

\section{Hazy data}

Long before the current interest in black carbon, an accidental observation by Warren led him to do some pioneering work on the pollutant. In 1980, he and Warren Wiscombe of the National Center for Atmospheric Research in Boulder, Colorado, were having trouble developing a mathematical model of snow reflectance, or albedo. The two couldn't make their calculations align with the latest albedo measurements in the Arctic because the snow in their study was reflecting less light than expected. "It turned out the snow was being collected downwind from a diesel generator," Warren says.

Warren went on to collaborate with Antony Clarke at the University of Washington, who organized the first survey of black-carbon deposition in the Arctic, largely using samples collected by researchers who were going there for other reasons. On the basis of those data, Clarke concluded in 1985 that soot could have a measurable effect on the Arctic climate ${ }^{3}$. But his paper had little influence until Jim Hansen, the man known for alerting the world to the threat of $\mathrm{CO}_{2}$ pollution, pressed the issue years later.

In 2000, Hansen, director of New York's Goddard Institute for Space Studies, proposed ${ }^{4}$ 
Stephen Warren uses snow from Canada's Ellesmere Island to look at effects of soot on the climate.
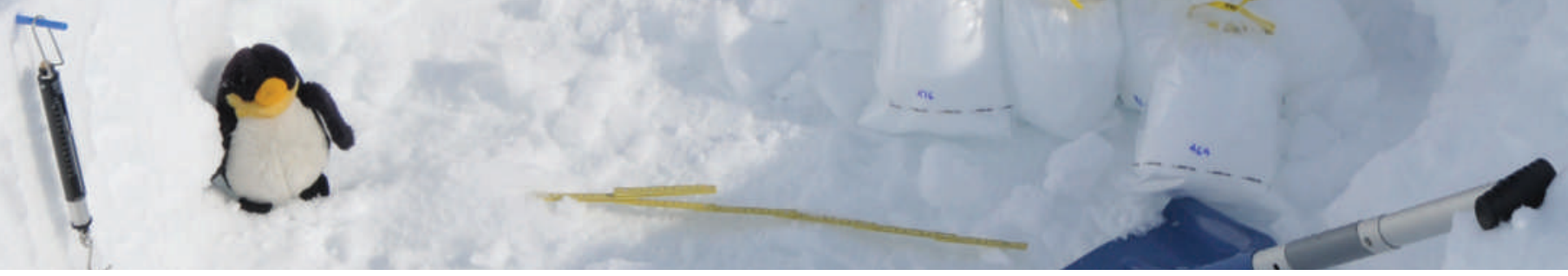

that the quickest way to combat global warming was to reduce black carbon, methane and other powerful warming pollutants that could be controlled more easily, and to greater effect, than $\mathrm{CO}_{2}$. Other studies soon followed. Building on earlier research on Californian smog, Mark Jacobson of Stanford University, California, reached a similar conclusion the following year ${ }^{5}$. He has since become a leading advocate for curbing black-carbon emissions and was invited to make his case before a congressional committee chaired by California Democrat Henry Waxman in 2007. Waxman, who is now chairman of the House energy and commerce committee, took the message on board. In a comprehensive climate bill that was passed by the House of Representatives last week, he calls on the US Environmental Protection Agency to analyse potential black-carbon strategies.

Jacobson calculates that humans have pumped enough pollutants into the air to warm the planet by about $2^{\circ} \mathrm{C}$. More than half that effect, however, is masked by other aerosol pollutants - including sulphates and light-coloured soot particles - which cool the planet by reflecting sunlight and seeding clouds. Jacobson estimates that altogether, the climate has warmed $0.75-0.85^{\circ} \mathrm{C}$ and black carbon is responsible for $0.25^{\circ} \mathrm{C}$ of that.

"In other words, you could control up to $30 \%$ of global warming if you could control soot," he says. Given that black carbon has its strongest effect in the Arctic, he suggests that such a strategy could slow sea-ice retreat until international controls on greenhouse gases kick in. "It's the only mechanism that you have," he says, "in the absence of putting in a bunch of refrigerators" (see 'Stopping the soot').

A recent study of the Arctic supports Jacobson's assessment. Drew Shindell, a modeller at the Goddard Institute, recently used a coupled ocean-atmosphere climate model to reconstruct twentieth-century influences on climate, or forcings, with and without black carbon. His results suggest that increases in black carbon from Asia and reductions in sulphate pollution have caused about $45 \%$ of the observed warming in the Arctic ${ }^{1}$. In Ramanathan's global assessment ${ }^{2}$, the forcing from black carbon equals 0.9 watts per square metre, which is more than the forcing from methane and $55 \%$ of that from $\mathrm{CO}_{2}$.

These numbers are much higher than the estimates produced by the Intergovernmental Panel on Climate Change (IPCC) in its 2007 report. The IPCC pegged the direct influence of black carbon - not including its ability to speed the melting of ice - at 0.05 to 0.35 watts per square metre (ref. 6). Overall, the effect of all aerosols - both the heat-absorbing black carbon and the reflective light-coloured ones produces a net cooling of 0.5 watts per square metre, according to the panel. That's enough to offset roughly one-third of the warming driven by $\mathrm{CO}_{2}$, but the estimate comes with a huge uncertainty range of $0.1-0.9$ watts per square metre. It also does not include the indirect effect that aerosols have on cloud particles.

Last month, Gunnar Myhre, a climate modeller at the Center for International Climate and $\stackrel{\infty}{\propto}$ Environmental Research in Oslo, attempted to lessen the uncertainty. He compared global aerosol models with observations derived from NASA's ground-based AERONET system, a network of passive aerosol sensors, as well as those from the MODIS (Moderate Resolution Imaging Spectroradiometer) instruments on NASA satellites. After accounting for historical emissions and tweaking the way his model handled clouds, Myhre produced a new estimate ${ }^{7}$ of 0.3 watts per square metre of cooling and halved the IPCC's uncertainty range. In explaining his lower estimate for net cooling, Myhre notes that black-carbon emissions have increased roughly sixfold in the industrial era, whereas reflective aerosols have only increased three- or fourfold.

\section{Questions in the clouds}

Although few doubt that black carbon has a warming effect, particularly in icy regions, some scientists are concerned that the policy debate is getting in front of the science. Uncertainties abound about everything from current and historical emissions to the actual chemical and physical processes that are driving black carbon's influence on snow and in the atmosphere.

For his part, Hansen says that there have been some "excessive claims" about black carbon. He calls greenhouse gases "the predominant 
cause" of global and Arctic warming and believes methane remains the number two forcing agent. At the same time, he says soot's effect is amplified over snow, which means the numbers put forth by Shindell cannot be ruled out. "Assuming greenhouse gases are reined in," he says, "other things that we can do such as reducing black-carbon emissions will be useful."

All this uncertainty has put a premium on solid information, which is why Warren and his colleagues set out in 2006 to conduct the first survey of black-carbon deposition in the Arctic. Since then, they have collected samples in Siberia, Greenland and Alaska, as well as at the North Pole. In their most recent trip in April, they hired a ski plane in Inuvik in Canada's Northwest Territories and flew east, setting down on lakes, tundra and sea ice as well as on fields of permanent ice.

Each of the team's sample pits captures an entire season of snow, providing clues about when different kinds of black-carbon pollution were deposited. They plan to feed this vast new resource to climate modellers, who are still trying to sort out ways that black carbon could affect temperatures.

The samples that Warren's team have collected tell only part of the story. Researchers have also used instruments on the ground, on planes and on satellites to measure soot in the air. But the task is particularly difficult because soot's darkness makes it hard to detect.

NASA hopes to get a better fix on black carbon around the globe when it launches the Glory satellite next year. A passive aerosol sensor will scan the atmosphere using seven wavelengths from visible light to short-wavelength infrared. It won't be able to pinpoint the amount of black carbon at specific altitudes, but it should be able to measure the total concentration from the ground up with an accuracy of 3\%, says the Goddard Institute's Brian Cairns, who designed the instrument.

Other clues to black carbon's influence are coming from deep below the surface of Greenland, where ice layers record how much soot wafted around the Arctic each year since before the industrial revolution. In 2007, Joe McConnell, a hydrologist at the Desert Research Institute in Reno, Nevada, measured black-carbon concentrations within an ice core from central Greenland dating back to 1788 . He found a sevenfold increase between 1850 and about 1910, particularly in winter. Soot levels fell after that until about 1950 and then largely remained close to pre-industrial levels ${ }^{8}$. These data, and findings from a second Greenland core, seem to align fairly well with estimates of historical emissions in North America, a likely source of the soot.

\section{Stopping the soot}

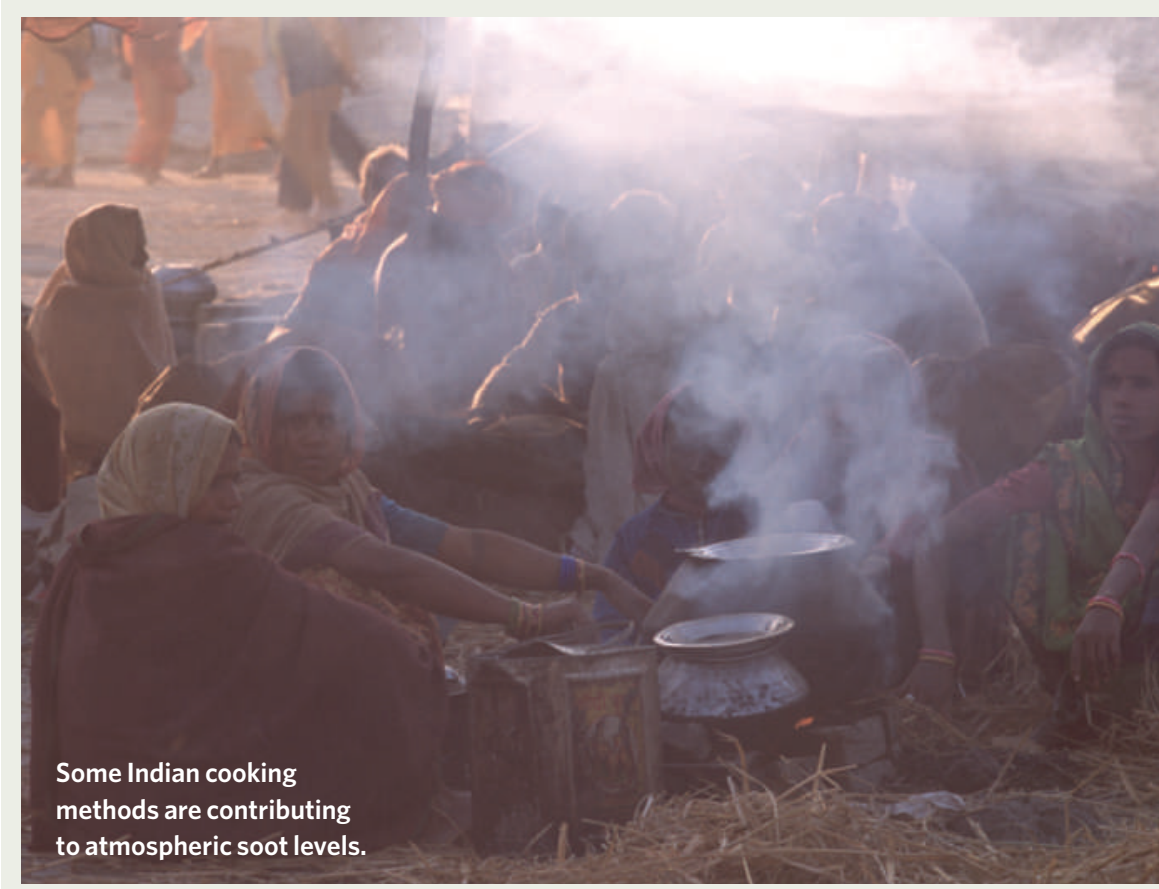

Last month the eight-nation Arctic Council appointed a task force to look at ways to reduce black carbon and other key pollutants responsible for rapid Arctic warming. It was a sign that the scientists pushing the link between black carbon and climate (see main article) are getting their message through to governments. The question faced by the council, and by policy-makers across the world, is what to do.

Black carbon, a primary component of soot, is a ubiquitous product of incomplete combustion, formed by natural forest fires, motor vehicles, coal plants and myriad other sources. Soot contains both black carbon and light-coloured particles that cool the planet; smoke produced by sources such as cooking stoves and diesel engines tends to be rich in darker particles. Reducing black-carbon emissions isn't a technical problem - modern stoves and filters can do most of the work - so much as an issue of governance and resources.
"Black carbon is perhaps the biggest, fastest bite we can take out of the climate problem," says Durwood Zaelke, who heads the Institute for Governance and Sustainable Development in Washington DC and has helped spearhead the movement internationally. "It needs, however, to be followed with aggressive regulatory action."

Global soot emissions have been rising steadily since the mid-1800s, although in recent decades the source of emissions has shifted from industrialized to developing nations. Pinning down actual emissions is difficult, but Tami Bond, a researcher at the University of Illinois, UrbanaChampaign, estimates that diesel combustion and residential fuel use (from coal, wood and agricultural debris) each produce roughly onequarter of the total; another $40 \%$ comes from wildfires and controlled agricultural burning; various industrial sources make up the remainder. Industrialized nations could clean up fossil fuels further and reduce agricultural emissions at home. But much of the focus will be on developing countries. The hope there is that current concerns over climate change will energize existing efforts to clean up diesel emissions and replace inefficient cooking stoves.

The precedent is there. China delivered roughly 150 million stoves to rural areas in the 1980s and early 1990s in an effort to reduce fuel use, says Kirk Smith, a rural energy expert at the University of California, Berkeley. Smith is working with local communities to encourage the use of locally produced, clean-burning biomass stoves, which reduce emissions of carbon dioxide, methane and other dangerous compounds. The impetus for the work has been to improve public health and reduce greenhousegas emissions, but the new attention on black carbon doesn't hurt, says Smith. "It's sort of the pollutant of the month and you need to take advantage of what's on people's minds." 
Taken at face value, it is difficult to match up the Greenland records with the contention that black carbon is now a major player in the Arctic. Arctic temperatures have surged in recent decades, when black-carbon levels have all but returned to historic levels.

McConnell cautions against reaching too strong a conclusion about black carbon on the basis of his two published cores. And he has already started analysing another pair of ice cores from Alaska. The amount of soot in snow depends both on how much is emitted and on how it gets transported. There is no way to differentiate changes in one from the other on the basis of just a few sites.

\section{Primed to melt}

Arctic circulations might have shifted at some point, or Greenland may simply not be representative of the entire Arctic. Variations on both arguments have been used to explain the apparent discrepancy. Another possibility is that the Arctic is more sensitive today than it used to be: decades of warming may have primed the climate system for early spring thaws.

"If you melt the snow just a few days earlier, that's quite a dramatic effect already," says Andreas Stohl, a researcher at the Norwegian Institute for Air Research in Kjeller who has been studying how black carbon gets into the Arctic. "The same is true for sea ice. It may be melting anyway, but black carbon can cause more melting and earlier melting. That has quite a big effect."

Last year Stohl led a project called POLARCAT, which involved using aircraft and satellites as part of an intensive mission that sampled Arctic aerosols. The project documented a number of smoke plumes from agricultural activities and open burning in Siberia. Such findings support data collected by Warren and his colleagues, suggesting that black carbon from fires - rather than industrial sources - has a dominant role during the melting season in the Arctic .

Those results, which surprised some researchers, could help explain how reduced levels of black carbon today could nevertheless have a strong influence on temperatures. Agricultural fires rarely happen during the dark Arctic winter, when black carbon has little effect; they tend to occur during the spring and summer, when the dark soot particles are particularly effective at melting snow.

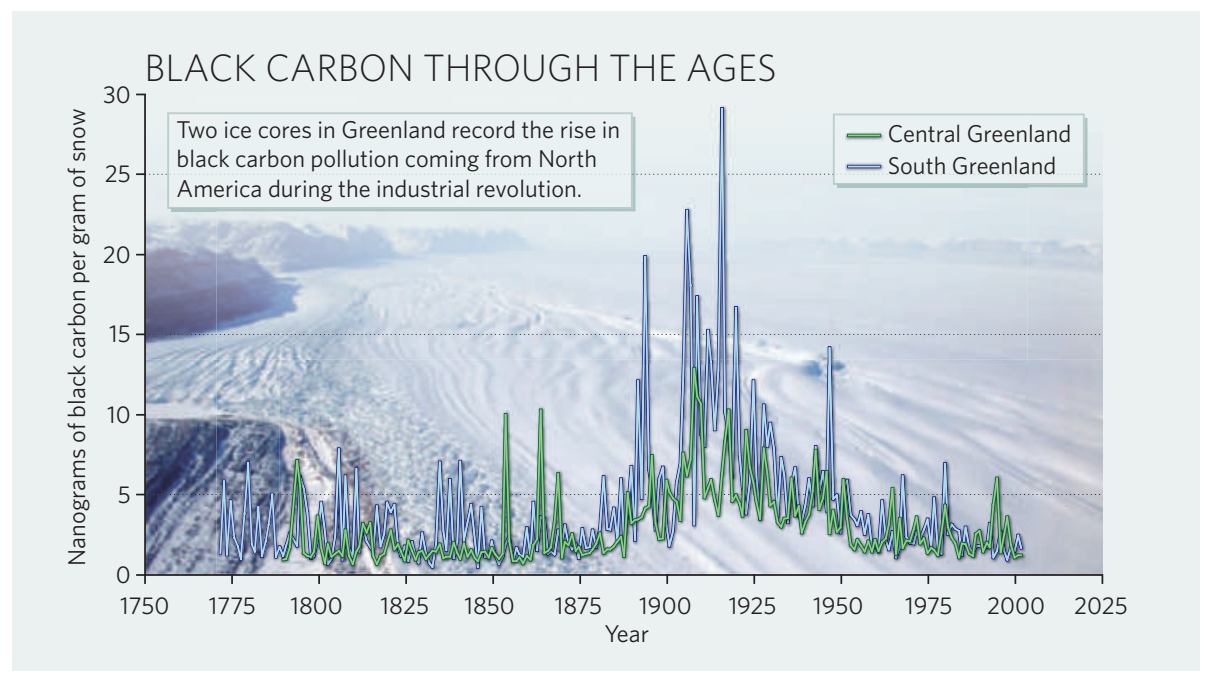

The story is different in southeast Asia, where China and India are in the midst of rapid development that combines industrial-scale fossil-fuel burning with extensive use of coal, wood and crop residues for home heating and cooking. The lowly cooking stove may contribute about $40 \%$ of the black-carbon pollution in China and about two-thirds of the total in places such as India, Pakistan and Bangladesh, says Ramanathan.

Surabi Menon, a researcher at Lawrence Berkeley National Laboratory in California, was among the first, with Hansen, to dig into the effects of black carbon in southeast Asia. Using general circulation climate models to test the effects of aerosols in 2002, they found that black carbon and other particles could help explain droughts in northern China and flooding in southern China ${ }^{10}$. Menon has recently finished some modelling indicating that black carbon could be responsible for roughly one-third of the glacial retreat in the past two decades.

Ramanathan took things a step further in March 2006, leading a team that sent a trio of unmanned aerial vehicles to sample black-carbon levels above the Indian Ocean ${ }^{11}$. Building on these results, he suggests that the Himalayas are hit twice: in addition to the direct effect on glaciers, black carbon and other aerosols also reduce snowfall by inhibiting the Indian monsoon $^{2}$. One effect is that black carbon absorbs sunlight high in the atmosphere over the Indian Ocean, which shades the ocean surface and cuts down on evaporation. At the same time, it cools the continent enough to weaken the monsoonal winds from the Indian Ocean. Overall, those changes contribute to glacial retreat by denying precipitation that would otherwise replenish the snowpack each year.

Ramanathan now heads a consortium involving scientists from countries such as India, China, Japan and South Korea that is trying to document effects in the Himalayas, the source of the region's fresh water. The team is even detecting strong signs of soot around Mount Everest.

"We're finding as much black carbon at altitudes of 3-6 kilometres as you are finding in downtown Los Angeles," he says, suggesting that the problem seems to grow the more he looks at it. Ramanathan is already convinced of the need to act on black carbon, although he realizes that effecting change in villages and cities across southeast Asia won't be easy. "Politically, of course, it's a tough issue," he says. "Thank goodness I'm not a politician." Jeff Tollefson covers climate from Nature's office in Washington DC.

1. Shindell, D. \& Faluvegi, G. Nature Geosci. 2, 294-300 (2009).

2. Ramanathan, V. \& Carmichael, G. Nature Geosci. 1, 221-227 (2008)

3. Clarke, A. D. \& Noone, K. J. Atmos. Environ. 19, 2045-2053 (1985).

4. Hansen, J., Sato, M., Ruedy, R., Lacis, A. \& Oinas, V. Proc. Natl Acad. Sci. USA 97, 9875-9880 (2000).

5. Jacobson, M. Z. Nature 409, 695-697 (2001).

6. Forster, P. et al. Climate Change 2007: The Physical Science Basis (eds. Solomon, S. et al.) Ch. 2, 165 (Cambridge Univ. Press, 2007).

7. Myhre, G. Science doi:10.1126/science.1174461 (2009)

8. McConnell, J. R. et al. Science 317, 1381-1384 (2007).

9. Hegg, D. A. et al. Environ. Sci. Tech. 43, 4016-4021 (2009).

10. Menon, S., Hansen, J., Nazarenko, L. \& Luo, Y. Science 297, 2250-2253 (2002).

11. Ramanathan, V. et al. Nature $448,575-578$ (2007).

\section{See Editorial, page 12.}

